\title{
MJN WHAT CAN NURSES DO TO IMPLEMENT LEAN HOSPITALS?
}

\author{
Bernadetta Eka Noviati*, Birgitta Dyah Yuliati \\ School of Health Sciences of Panti Rapih, Yogyakarta, Indonesia \\ *Corresponding Author's Email: eka.vie@gmail.com
}

\begin{abstract}
Background: Lean hospital is a very rational hospital management practice to be run to provide effective and efficient services for patients. Nurses have a major role to play in the application the lean hospital. Purpose: The aim of this study is to explore the factors that need to be implemented by nurses in lean hospial. Method: Qualitative research with data collection techniques of deep interview was done. The Focus Group Discussion (FGD) was on five informant who is a nurse manager at a private hospital in Indonesia. Five Informants (I) were selected by purposive sampling. Results: The study results found three themes that nurses can do to be able to apply lean hospitals in the nursing field, namely: 1) managerial work processes; 2) fulfillment of nursing work facilities and infrastructure; and 3) to work effectively and efficiently. Conclusion: Lean hospitals can be implemented by nurses to be able to make nursing services in hospitals more effective and efficient by reducing managerial arrangements, and reducing patient waiting time for services.
\end{abstract}

Keywords: Lean Hospital, Nurses, Implementation

\section{INTRODUCTION}

The need for a healthy life is a vital hope for every human being. If someone is having problems in health, then that person will be looking for a place to get health care, one of them is going to the hospital. The hospital is a health care provider facilities organized by the government, and private hospital. At present it is a challenge for hospitals to be able to provide the best service by following the established rules. The provision of health services by government regulations with a standard and fare system encourages the hospital management to think critically so that the hospital is able to provide the best possible service for patients and at the most cost-efficient means possible.

The concept of lean management is a continuous effort that can be done by hospitals to eliminate drawbacks and increase the added value of all products in the hospital services. This concept becomes a rational choice to be applied managerially in a hospital. The concept of lean hospital can be implemented with the principle of eliminating limitations in all lines or service units in the hospital. Such continuous improvement efforts can increase added value for patient services in hospitals (Gasper \& Fontana, 2011).

According to Graban (2012), lean hospital is a management system with a philosophy of changing perspective so that hospitals become more organized by improving the quality of service to patients, reducing errors, and reducing waiting times. Thus all activities carried out in the hospital are expected to be able to totally dispose of all waste and provide services in respect of people. Respect to people means respect for patients, doctors, nurses, all employees, and the stakeholders of the hospital and its environment.

Nursing services are at large, broad part of the overall hospital health services. Lean implementation in the field of hospital care would be a big impact for the management system in hospital. Thus the purpose of this study is to explore the implementation of lean hospitals run by nursing in one of the private hospitals in Indonesia.

\section{METHODOLOGY}

The study was conducted with a qualitative study method with data collection techniques conducted with deep interviews and Focus Group Discussion (FGD) on 
five informants who are nurse managers in a private hospital in Indonesia. The five informants (I) selected by purposive sampling were the nurses of top managers, nurses of middle managers, and nurses of lower managers. The research analysis was carried out manually by interpreting the data from the FGD results and deep interviews, and processed by involving examination, sorting, categorizing, evaluating, comparing, synthesizing, and pondering coded data along with reviewing standards and recording all existing data (Neuman, 2014). The results of the study are presented in a narrative.

\section{RESULTS}

An analytical process was employed to find out things that nurses can do in implementing lean hospitals, it can be classified into three themes, namely: 1) Managerial nursing work processes; 2) Fulfillment of nursing work facilities; and 3) Work effectively and efficiently.

\section{Theme 1: Managerial Nursing Work Process}

The managerial work process theme is built from five sub themes which include: 1) Organizing workflow, teamwork and managing personnel; 2) Planning and socializing change; 3 ) Review the staff of the ministry; 4) Organization of training; 5) Setting efficiently schedule and coordinate the routine.

Arranging the flow and work team in nursing services were carried out in the nursing work unit to provide services to patients as efficiently as possible in accordance with the existing SOP (Standard Operating Procedure). In general, the personnel needs for the nursing field are sufficient, so that it can be scheduled as a team work. The flow of nursing services is also improved in this manner. As result the patients do not have to go back and forth in getting services. The service process will be completed first in the Emergency Unit, including the process of waiting for laboratory results, and then it is determined whether the patient will go home, be hospitalized, or be referred.

"Nurses work according to SOP, if someone forgets, nurses will remind who does not work according to standards." (I2)

"Labor arrangements for midwifery units according to priority needs, sufficient inpatient workforce, sufficient outpatient units, unless referral becomes difficult. The ER(Emergency Room) is quantitatively sufficient, qualitatively also sufficient, starting to be regulated as needed, qualitatively not approaching the standard. 2020 is being pursued. " (I1, I2, I3, I4)

"The workflow of nurses is also being improved, so that there is no back and forth service, finish first in the emergency unit, wait for the laboratory, then the next steps are determined, whether to go home, hospitalize, or referred." (II)

In the process of implementing lean hospital in the nursing field some managerial changes are needed. The changes made are not entirely easy to accept and implement, especially for senior nurses who feel they are in a comfort zone. But the policies and rules that must be carried out by every nurse, resulting in desirable changes which can be implemented. The socialization was carried out to be able to explain the policy towards the change.

"The Midwifery Unit wants to create a culture of inpatient every morning around as in the inpatient unit, but it is difficult to follow, following changes is not easy." (I3)

"Making changes in the Inpatient Unit is still difficult. Positioning something new is still difficult. The difficulty is precisely in my friends who are seniors. Changing habits that used to be like this is difficult, rejecting the difficulty to bring about changes as most them are already comfortable, feel good, feel the best, just like this the patient is satisfied, why should change? Even though there are still many that are lacking and must be changed. " $(11,12)$

"... but finally because this is their job as an employee of the agency, yes, in the end I don't want to have to follow the rules. When things clashed with the rules, finally they want. Units that have this comfort zone must be confronted with rules or regulations. With continuous socialization, eventually it will also change. "(I4)

Staff reviews are also carried out to improve the performance of nurses from day to day. As a nursing manager a review of SOP in carrying out services must be reviewed continuously, so that providing excellent service to patients becomes a habit. Staff briefing was also held and they were also reminded of matters related to excellent service.

"As managers we have to remind staff, motivate, give reviews about $S O P$, review excellent service, staff briefings every morning, are done as evaluation process. A reminder regarding excellent service. Alert nurses when work is not done in accordance with the 
standards." (I1, I2)

Nursing staff development is also carried out by arranging various trainings that must be followed by each nurse. Organizing training or including training is intended so that nursing services provided by nurses are at optimal. The training programmed for nurses can be both basic and advanced training. Training opportunities are provided for nursing staff in accordance with the needs of both inpatient nurses, emergency room nurses, nurses or midwives in midwifery units, operating theater nurses, and outpatient nurses.

"... Training for nursing staff according to needs. Both in the inpatient unit, outpatient unit, emergency room, operating room, midwifery unit ... "(I1)

"Training is sometimes internal, sometimes external, if for nurses and basic training, then the training is usually done internally, but there are also many who participate in training or out seminars." (I2)

Scheduling and coordinating the implementation in a single unit or between units must be carried out routinely. Schedule must be set by each nurse head and must be spaced effectively so as to reduce the number of nurses working overtime. If there are nurses who are scheduled to be less effective, then the nurses will be arranged to help other wards. Power management is also adjusted to the condition of the ward. If there are not many patients in the ward, nurses who still have a lot of leave are allowed to take their leave.

"... ineffective policies, we empower to help the unit where it is inconvenient ..." $(12,15)$

"Managing nursing staff, when there are few patients and it turns out that there are many who perform their duties, then we will provide opportunities for those who still have the right to take leave. Then iffor example the patient is just a few, the amount of night watch is reduced" $(I 2, I 4)$

"We have made Morning, Morning-Evening and Evening shift schedules. So there are tricks to overcome so that even overtime hours are reduced. "(I3)

\section{Theme 2: Fulfillment of Nursing Work Facilities}

On the theme of fulfilling nursing work facilities is building two subthemes, namely: 1) Preparing equipment in one trolley; and 2) Make sure the equipment is in good condition and ready to use.

Equipment or all equipment arranged in a trolley makes it easy for nurses to work efficiently. With this equipment, once the nurse needs certain equipment, the nurse does not have to go back and forth to retrieve the equipment needed.

"Begin by preparing the equipment in one trolley, traveling to patients with that trolley without having to go back and forth." (I5)

Support equipment maintenance services are also carried out regularly for maintenance, thus all the equipment used for measurement of results were valid. After the use of such equipment will be cleaned, reorganized in place, so when will be used again ready to use.

"... available and regulated only devices that are effectively used, which cannot be effectively borrowed or lent." (I3)

"Monitoring the functional instruments, so that they are not missed in maintenance such as calibration schedules. If there is an immediate problem, it can be quickly dealt with, so that the measurement results of the tools become precise and accurate thus it becomes effective in providing services. "(I2)

"Invite all nurses and midwives when they use equipment to be re-prepare them, so that the following users are immediately ready to operationalize the equipment." (I3)

\section{Theme 3: Work with Effective and Efficient}

The theme of working effectively and efficiently was built with four sub-themes, namely: 1) The use of one sheet of tissue to dry hands when washing hands; 2) Prepare the patient documents again by working first; 3 ) Providing emergency medicine that is often used in stock cabinets; and 4) Using social media tools to communicate and coordinate.

Efficiency efforts at the nurse's hand washing facility were developed with SOP using one sheet of tissue in drying. This is socialized and cultivated for all staff. Thus the cost efficiency of using tissue can be reduced.

"A simple example is the use of a tissue to wash your hands just one sheet, there is an SOP."(I3)

Preparation of patient discharged begins with the preparation of patient documents. For patients who will return the next day, documents must be prepared in advance. The administration can help with the patient's administration first, and the nurse can prepare the patient's needs for discharge, including documents, 
medicine, education, etc.

"For example, when patients go home, when they want to go home, the condition is good, we call in the morning first, direct accounts, so the doctor will visit the account later. So later longer waiting for account calculation can be avoided. So it saves hours. We have already telephoned the doctor to prepare for going home, we have prepared the patient to go home, then when the doctor's visit is over, he can go home immediately. So the patient is released fast. "(I5)

"... if there are already patients who are planning to go home, the doctor will prescribe the medication for home. So this reduces the waiting time for inpatients to go home." (I3)

For the efficiency and effectiveness of nursing services, emergency medicines are also prepared on the trolley. If there are patients who need these drugs, nurses can immediately give them according to medical advice, without having to go back and forth to the pharmacy to take these drugs.

"As for drugs, because we have drugs that are indeed in Kid's Emergency it has been prepared and we have an inventory every day so that it is smooth." (I3)

"There is a special officer who regulate the availability of stock, so be assured." (I2)

To develop service efficiency and effectiveness, nursing also utilizes social media to convey coordination and information. Any urgent or noteworthy information known to all nurses, can be shared by WhatsApp group. For coordination of nursing managers between units, also using WhatApp nursing management groups can be utilized. Thus all can be conveyed quickly.

"Continuous evaluation and coordination. Can go through WhatsApp groups. "(I3)

"We often use WhatsApp to communicate, whether to convey information, encourage coordination between units, or information that is managerial." (II)

\section{DISCUSSION}

\section{Managerial Nursing Work Process}

Nursing services require a structured and professional organization. The nursing service system developed by a hospital is must be adjusted according to the needs and resources present. Regarding human resources especially nursing leaders are crucial. One of the nurses' competencies in hospital is leadership competency. Nurse managers must have communication competence, the ability to delegate tasks, arrange assignments, select and assign nursing staff, create an effective organizational work culture, and have flexibility (Nursalam, 2015). The nursing unit can also develop lean management in providing services to patients. Positive outcomes can be found in hospitals that implement lean management systems (Cacciatore $e t$ al., 2019)

Professional work team arrangements in service, effective workflow management, and effective workforce management are expected to be able to improve the efficiency and effectiveness of care services. Implementation of lean hospitals can result in increased operational efficiency and quality improvement, including in the field of care (Harrison et al., 2016). Care services needed for efficient regulation therefore necessitates that resources to be properly preserved.

The process of change in nursing management is not simple and easy. Moreover they are not supported by the senior nurses who are reluctant to change because they feel they are in a comfort zone. However the planning, process, and continuous socialization efforts carried out by the nursing management, are able to drive changes towards improvement. Change causes high pressures in carrying out hospital operations (Hugh, Gliebe \& Sendlhofer, 2019). Other problems are also faced by management which due to the employees who are resistant to change (Regis, Santos \& Gohr, 2019).

The nursing management must control the functioning of administration to improve the efficiency and care of nursing by carrying out a continuous review of service standards and also training for improving nursing performance. Training for nurses can have a direct impact on skills that are useful for nursing services. Leadership commitment and active support for the implementation of lean hospitals have impact the improvement of the quality of nursing services (Harrison et al., 2016).

Setting work schedules efficiently must be done by all nurse managers. Thus the nursing care given to the patient can take place not only effectively but also efficiently. The personnel system is developed according to needs by empowering existing resources, arranging and scheduling efficiently, even if needed, can also manage the workforce by supplying nurses from other units that are relatively not busy. Human resource management of nurses must reflect the policies, work 
load factor, the interest of the staff. This arrangement can be reviewed periodically according to the situation and conditions (Swanburg, 2000).

\section{Fulfillment of Work Facilities and Infrastructure}

Nursing facilities and work infrastructure hold the key to the success of services to be effective and efficient. By providing quality and good service support facilities, it is expected that the results of the medical performance will be valid. A well-maintained system also encourages nurses to work quickly and precisely. By providing adequate work facilities, lean hospitals in the nursing field can also be achieved, thus nurses will work effectively and efficiently. The service process that flows into a service product in nursing services raises good quality services. In this way, economical financing is also achieved, more efficient service times, shorter waiting times is achieved so that satisfaction is reached for all parties (Graban, 2012; Gaspers \& Fontana, 2011).

To ensure that support facilities for nursing services are well maintained also require a control mechanism from the nurse manager. These tasks can be set forth through SOP which can be carried out routinely by parties that have been appointed or given authority. Nursing managers can also control their staff in managing the time used so as to increase the productivity of hospital services (Nursalam, 2015). It also encourages the achievement of lean hospitals in the nursing field.

\section{Effective and Efficient Work Process}

The implementation of nursing services is expected to be carried out efficiently and economically, but adhering to applicable standards. Efficiency practices in nursing include carrying out hand washing using tissue facilities as a dryer with just one sheet. The procedure is a real lean hospilal practice that can be carried out in the nursing field. The practice is in accordance with research conducted by Shortell et al., (2018) that the length practicing performance of a hospital with lean management is reported to have a positive impact on each employee.
Management of resources to prepare patients for discharging many parties can have an impact on reducing patient waiting time when returning home, because service is fast. Preparing discharge administration which involves resources from several service units, encourages lean hospitals to be implemented especially in the nursing field. The functions of HR (Human Resource), finance, and information technology are positively related to the implementation of lean management in hospitals (Shortell et al., 2018).

Effective communication in nursing also supports the achievement of efficient services. All information and coordination regarding services and development can be conveyed quickly through social media. Whtasapp groups can be empowered to share information and coordinate quickly in accordance with the results of Hamidi, Mahendra \& Denecke's (2019) research that digital technology can support communication and service delivery for patients in hospitals.

\section{CONCLUSION}

Nurses can support the implementation of lean hospitals with the aim of being able to provide more efficient services for patients, as well as reducing waiting times. The things that can be done to apply lean hospitals in the field of nursing is to manage nursing resources properly, optimize the regulation of nurse resources efficiently, provide adequate support facilities for services, prepare things to decide on long-lasting services and back and forth, and optimize the willingness to support services.

\section{Conflict of Interests}

The authors declare that they have no conflict of interest.

\section{ACKNOWLEDGEMENT}

The researcher would like to thank the Director of Panti Rini Hospital in Yogyakarta, Indonesia. Appreciation and thanks are also given to all the nursing management team Panti Rini Hospital who have willing participated in this study. Their cooperation and willingness are appreciated. God bless.

\section{REFERENCES}

Cacciatore, P., Calabrò, G.E., Mogini, V., Moraca E., Makishti O., Campanella P., Ricciardi W. \& Specchia, M.L. (2019). Lean thinking in the hospital setting - Results of a systematic review of literature. Igiene E Sanita Pubblica, 75(1), pp 29-50.

Gasper, V. \& Fontana, A. (2011). Lean Six Sigma for Manufacturing and Service Industries . Jakarta: PT Gramedia Pustaka Utama. 
Graban, M. (2012). Lean Hospital Improving Quality, Patient Safety and Employed Engagement. New York: CRP Press Taylor \& Francis Group.

Hamidi, M., Mahendra, P. \& Denecke, K. (2019). Towards a Digital Lean Hospital: Concept for a Digital Patient Board and Its Integration with a Hospital Information System. Studies In Health Technology And Informatics, 264, pp 606-610.

Harrison, M.I., Paez, K., Carman, K.L., Stephens, J., Smeeding, L., Devers, K.J. \& Garfinkel, S. (2016). Effects of organizational context on Lean implementation in five hospital systems. Health Care Management Review, 41(2), pp 127-144.

Hugh, E., Gliebe, W. \& Sendlhofer, G. (2019). Qualitative analysis of lean management in healthcare: perspectives of Austrian and Swiss experts]. Zeitschrift Fur Evidenz, Fortbildung Und Qualitat Im Gesundheitswesen, 143, pp 8-14.

Neuman, W.L. (2014). Sosial Researh Methods: Qualitative and Quantitative Approache, Seventh Edition. Harlow: Pearson Education Limited.

Nursalam (2015). Manajemen Keperawatan. Aplikasi dalam Praktik Keperawatan Profesional. Jakarta: Salemba Medika.

Regis, T., Santos, L. \& Gohr, C. (2019). A case-based methodology for lean implementation in hospital operations. Journal of Health Organization and Management, 33(6), pp 656-676.

Shortell, S., Blodgeett, J., Rundal, T. \& Kralovec, P. (2018). Use of Lean and Related Transformational Performance Improvement Systems in Hospitals in the United States: Results From a National Survey. Joint Commission Journal on Quality and Patient Safety, 44(10), pp 574-582.

Swanburg, R. (2000). Pengantar Kepemimpinan dan Manajemen Keperawatan untuk Perawat Klinis. Jakarta: Penerbit Buku Kedokteran, EGC. 